\title{
Immune Complexes in Serum and in Cerebrospinal Fluid in African Trypanosomiasis
}

\author{
CORRELATION WITH POLYCLONAL B CELL ACTIVATION \\ AND WITH INTRACEREBRAL IMMUNOGLOBULIN SYNTHESIS
}

\author{
P. H. Lambert, M. Berney, and G. Kazyumba, World Health Organization \\ Immunology Research and Training Centre, Department of Medicine, \\ Hopital Cantonal, 1211 Geneva 4, Switzerland; Department of Parasitology, \\ University of Kinshasa, Zaire
}

\begin{abstract}
A B S TRACT The possible occurrence of immune complexes (IC) in serum and in cerebrospinal fluid (CSF) has been studied in 36 patients with African trypanosomiasis (Trypanosoma brucei gambiense). In serum, very high levels of IC were detectable by the ${ }^{125}$ I-Clq-binding and by the conglutinin-binding assays with positive results in 94 and $87 \%$, respectively, of untreated patients. Circulating IC were found in both early and late stages of the disease, without significant quantitative differences; their size was $15-25 \mathrm{~S}$. There was a significant negative correlation between $\mathrm{C} 3$ values and ClqBA. Our studies suggest that circulating IC occurring during trypanosomiasis may be the expression of a polyclonal $B$ cell activation. Indeed, there was a significant correlation $(P<0.001)$ between the levels of circulating IC and either the levels of IgM (mean value $12.5 \pm 7.2$ $\mathrm{mg} / \mathrm{ml}$ ) or with the levels of rheumatoid factor-like antiimmunoglobulin antibodies that were detected by solid phase radioimmunoassay in $74 \%$ of the patients.

IC were detected in 31 of 35 CSF samples, with a marked elevation in patients with definite involvement of the central nervous system as compared with earlier stages of sleeping sickness. The occurrence of IC in CSF was not related to an impairment of the blood-brain barrier as shown by analysis of $\mathrm{CSF} / \mathrm{serum}$ albumin ratios. The level of IC in CSF did not correlate with the serum level and,
\end{abstract}

This work has been supported by the World Health Organization, the United Nations Development Programme, World Bank, World Health Organization Special Programme on Research in Tropical Diseases, and by the Swiss National Science Foundation (grant No. 3.908.0.80).

Received for publication 19 March 1980 and in revised form 15 September 1980. therefore, circulating IC do not appear to cross efficiently an unimpaired blood-brain barrier. The analysis of IgG, IgM, and albumin concentrations in serum and CSF demonstrates a marked intracerebral immunoglobulin synthesis in patients with manifestations of meningoencephalitis. There was a correlation between CSF-Clq binding assay and this local IgG synthesis.

These data are consistent with a local formation of IC in CSF in patients with active meningoencephalitis. The results obtained in eight patients followed during therapy suggest that the presence of IC in CSF may be an indicator of a continuing central nervous system disease and that the quantitation of CSF-IC may be useful for monitoring patient care.

\section{INTRODUCTION}

The infection of man with Trypanosoma brucei gambiense is responsible for the development of sleeping sickness. It is still a serious health problem in many African countries (1). Two phases of the disease are generally recognized: first, there is a proliferation of trypanosomes in blood and in lymphoid tissues, then the parasites invade the central nervous system $(\mathrm{CNS})^{1}$ and induce a meningo-encephalitis. A major feature of trypanosomiasis is an intense proliferation of lymphocytes, particularly involving B cells and leading to an increased polyclonal synthesis of immunoglobulins $(2,3)$. This occurs soon after infection. The development of cerebral lesions

\footnotetext{
${ }^{1}$ Abbreviations used in this paper: CNS, central nervous system; CSF, cerebrospinal fluid; $\mathrm{Clq}_{\mathrm{qBA}},{ }^{125} \mathrm{I}-\mathrm{Clq}$ binding assay; IC, immune complexes; KgBA, conglutinin binding assay; Qalb, CSF/serum albumin ratio; $\mathrm{RF}$, rheumatoid factor.
} 
responsible for the typical clinical expression of sleeping sickness is a late manifestation of the disease and is associated with the appearance of $\operatorname{IgM}$ in the cerebrospinal fluid (CSF), which probably reflects an intracerebral IgM synthesis (4).

The pathogenesis of the tissue lesions in African trypanosomiasis is still largely unknown. Experimental studies have indicated that there is no direct toxic effect of the parasites in the infected tissues and that the host's immune response plays a major role in the triggering of inflammatory foci (5). The present investigation has been undertaken in order to analyze the involvement of immune complexes in this disease. Circulating immune complexes (IC) were first studied in relation to the patient's disease stage and to the expression of the polyclonal B cell activation. In particular, the correlation with the occurrence of rheumatoid factor (RF)-like antibodies was studied. IC were also found in CSF and their origin was questioned. The possibility of IC crossing from blood to CSF or of a local formation of IC within the CNS have been considered in relation to the functional state of the blood-brain barrier and to the local synthesis of immunoglobulins in CNS. The usefulness of the quantitation of CSF-IC for stage diagnosis and follow-up of patients with sleeping sickness has also been evaluated. Through these studies on African trypanosomiasis, it has been possible to approach two questions that are also relevant to other human diseases: (a) Does an intense polyclonal B cell activation generate circulating immune complexes in man? (b) Do IC cross an unimpaired blood-brain barrier?

\section{METHODS}

Patients. 82 serum samples and 34 cerebrospinal fluid samples from 36 patients with trypanosomiasis were collected in Zaire in the course of the regular activities of the Centre du Controle de la Trypanosomiase. In all the selected patients, the clinical diagnosis was confirmed by the microscopic demonstration of trypanosomes in blood, in lymph node aspiration fluid or in CSF. All these patients also had anti-trypanosome antibodies in serum. They were also submitted to a routine parasitological investigation. For some of our studies, the patients were classified according to the stage of the disease. Three different stages were considered: patients at stage I present hemolymphatic manifestations of the infection (enlarged lymph nodes, trypanosomes in blood, normal pattern of cerebrospinal fluid, no clinical sign of cerebral involvement); stage II is similar to stage I but trypanosomes appear in the CSF; stage III is characterized by neurological manifestations ("sleeping sickness") and abnormal CSF (trypanosomes, increased cell and protein content). Blood and CSF samples included in this study were collected for the routine diagnostic procedures. In particular, CSF samples were drawn for the routine detection of trypanosomes and not for the purposes of our investigation. Most of the serum and CSF samples were obtained before treatment. In a followup study, samples were also obtained during treatment and several months after treatment with melarsoprol (Arsobal, Rhone-Poulenc, Vitry, France). Blood was drawn from patients and allowed to clot for $2 \mathrm{~h}$. After centrifugation, the serum and CSF samples were frozen, stored, and shipped in liquid nitrogen. Control serum samples were obtained in Kinshasa from age-matched hospitalized Zairian patients suffering from schistosomiasis (eight), amebiasis (two), ascariasis (two), hookworms (two), lung cancer (one), and tuberculosis (two). Another group of control sera was obtained from 40 age-matched normal blood donors in Geneva. Five CSF samples were also obtained in patients from Geneva who had to undergo a myelography which requires prior removal of some CSF. These five CSF samples were considered as normal controls since no neurologic disease could be demonstrated in these patients. In addition, nine CSF and corresponding serum samples were obtained from patients hospitalized in Kinshasa for other parasitic diseases (malaria, schistosomiasis, filariasis).

\section{Detection of immune complexes in serum and in $C S F$}

Clq binding assay. The detection of immune complexes was performed in sera using the ${ }^{125} \mathrm{I}-\mathrm{Clq}$ binding test as described by Zubler et al. (6), but slightly modified as follows: in the first step, $50 \mu \mathrm{l}$ of serum was mixed with $100 \mu \mathrm{l}$ $0.2 \mathrm{M} \mathrm{Na}_{2}$ EDTA pH 8.3 containing $0.4 \%$ Tween 20. For the detection of Clq binding material in CSF, $100 \mu$ l of CSF was mixed with $50 \mu \mathrm{l}$ fresh normal human serum before adding $100 \mu \mathrm{l} 0.2 \mathrm{M} \mathrm{Na}_{2}$ EDTA pH 8.3, 0.4\% Tween 20. After incubation at $37^{\circ} \mathrm{C}$ for $30 \mathrm{~min}, 50 \mu \mathrm{l}$ of ${ }^{125} \mathrm{I}-\mathrm{Clq}$ and $500 \mu \mathrm{l} 3.6 \%$ polyethylene glycol (DAB, 7, 6,000 mol wt, Siegfried A.G., 4800 , Zofingen, Switzerland) were added. The results were corrected by subtracting the percentage of precipitation obtained with a normal serum pool. The mean corrected value for 40 normal human donors was $0.6 \pm 0.45 \%$ ( $\pm 1 \mathrm{SD})$.

Sera with high Clq-binding activity were treated with deoxyribonuclease I (DNase). 1 vol of serum was mixed with $1 \mathrm{vol}$ of DNase (1 $\mathrm{mg} / \mathrm{ml}$ in veronal-buffered saline, Worthington Biochemical Corp., Freehold, N. J.) and incubated for $3 \mathrm{~h}$ at $37^{\circ} \mathrm{C}$. The enzymatic reaction was stopped by adding EDTA $0.2 \mathrm{M}, \mathrm{pH} 7.0$ in borate buffer. Control sera were treated similarly except that the EDTA was added before the DNase. The digested and undigested material was tested for Clq binding activity.

Conglutinin-binding assay. The conglutinin binding assay was performed on serum according to Casali et al. $(7,8)$, using ${ }^{125}$ I-staphylococcal protein $\mathrm{A}$ as a labeled marker for the quantitation of conglutinin-bound IC. For the testing of CSF samples, CSF was diluted $1: 2$ in fresh normal human serum.

\section{Detection of anti-trypanosome antibodies}

Trypanosoma brucei brucei were obtained from lump 227 after a passage in irradiated mice. Trypanosomes were separated from erythrocytes on a DEAE column according to Lanham and Godfrey (9). Smears were prepared, dried, and fixed with ethanol. Serial dilutions of each serum or CSF sample were then tested for antibodies by indirect immunofluorescence using anti-IgG and anti-IgM conjugates (Nordic Immunological Laboratories, Tilburg, The Netherlands). 


\section{Quantitation of serum and CSF proteins}

IgG, IgM, albumin, and C3 were quantitated by radial immunodiffusion using commercially supplied immunodiffusion plates (Behringwerke AG, Marburg/Lahn, West Germany). The protein content was determined by the Lowry technique (10).

\section{Sucrose gradient ultracentrifugation}

Serum and five CSF samples from patients with trypanosomiasis were subjected to ultracentrifugation in a 10$40 \%$ sucrose gradient (borate buffer, $\mathrm{pH}$ 8.3) using an $\mathrm{SW}$ 65 rotor (Beckman Instruments, Inc., Spinco Div., Palo Alto, Calif.). The centrifugation was done at 50,000 rpm for $5 \mathrm{~h}$.

\section{Evaluation of the blood-brain barrier status and detection of an intracerebral immunoglobulin synthesis}

The CSF/serum concentration ratios (Q) of albumin (alb), IgG, and IgM (Qalb, QIgG, QIgM, respectively) were determined. The relative impairment of the blood-CSF barrier as reflected by an increased permeability to albumin was estimated from the Qalb values, as described by Tibbling et al. (11). The IgG index (QIgG/Qalb) was determined according to Schliep and Felgenhauer (12), in order to evaluate the intensity of the local production of IgG in the CSF compartment. The intracerebral IgG synthesis was also calculated using Tourtellotte's formula (13):

IgG synthesis (milligrams/100 ml)

$$
\begin{aligned}
= & \operatorname{IgG}_{\mathrm{CSF}}-\left(\frac{\mathrm{IgG} \text { serum }}{369}\right) \\
& =\left[\left(\text { albumin }_{\mathrm{CSF}}-\frac{\text { albumin serum }}{230}\right)\right. \\
& \left.\quad \times\left(\frac{\mathrm{IgG} \text { serum }}{\text { albumin serum }} \times 0.43\right)\right] .
\end{aligned}
$$

\section{Solid-phase radioimmunoassay for antiimmunoglobulin antibodies (RF)}

The assay for detecting antiimmunoglobulin antibodies using polyethylene tubes coated with rabbit IgG was described by Hay et al. (14) and was slightly modified for use in this study.

\section{Statistical analysis}

The data were analyzed using the Wilcoxon rank test, linear regression $(r)$, and the Spearman correlation test $(R)$.

\section{RESULTS}

Circulating immune complexes and C3 in human trypanosomiasis. A biological activity suggestive of the presence of immune complexes was investigated in serum from 36 patients, using the Clq binding assay $(\mathrm{ClqBA})$ and the conglutinin binding assay
(KgBA). There was an increased ClqBA in $94 \%$ of these patients, with a median value of $36 \%$ (Fig. 1). Values of $\mathrm{KgBA}$ were also increased in $81 \%$ of the patients with a median value of $64 \mu$ geq aggregated human gamma globulin/ml (Fig. 1). In both $\mathrm{ClqBA}$ and $\mathrm{KgBA}$, there was a very significant difference between the sleeping sickness group and either the group of other hospitalized African patients $(P<0.001)$ or the normal European control group $(P<0.001)$. There was a significant correlation between the results obtained with the two tests $(\mathrm{R}=0.51, P<0.001)$. The nature of the Clq binding material was further analyzed by ultracentrifugation of six serum samples on sucrose density gradient. The peak of C1qBA was found in 15-25S fractions (Fig. 2). The ClqBA was also measured in 10 samples, which were incubated in presence of DNase, and was not found significantly changed (undigested: $24.8 \%$; digested: $26.3 \%$ ). The levels of ClqBA and $\mathrm{KgBA}$ in serum were also analyzed according to the clinical stage at the time of diagnosis and of sample collection. At all stages, there was a significant increase in the values obtained in the two tests $(P<0.005)$. All patients at stage I were positive in both tests and there was no significant difference between the levels observed in the patients at various stages (Fig. 1).

In the 36 patients studied before treatment, serum C3 levels were measured. A significant decrease was observed in $67 \%$ of samples, with a mean value of $62.9 \pm 26.3 \%$ (Fig. 3). In other hospitalized African patients, the mean value was $105.4 \pm 33 \%$. There was
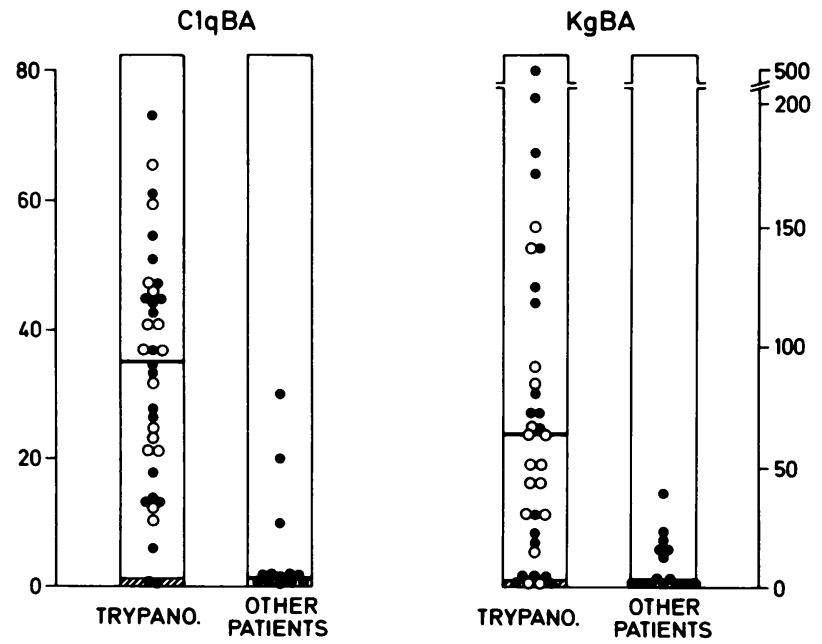

Figure 1 ClqBA (percent precipitated) and KgBA (micrograms equivalent aggregated human gamma-globulin per milliliter) activities in serum samples from patients with trypanosomiasis $(\mathrm{O}$, stage I or II; 9 , stage III) and from other hospitalized African patients. The normal range in European control group is indicated by the hatched area. 


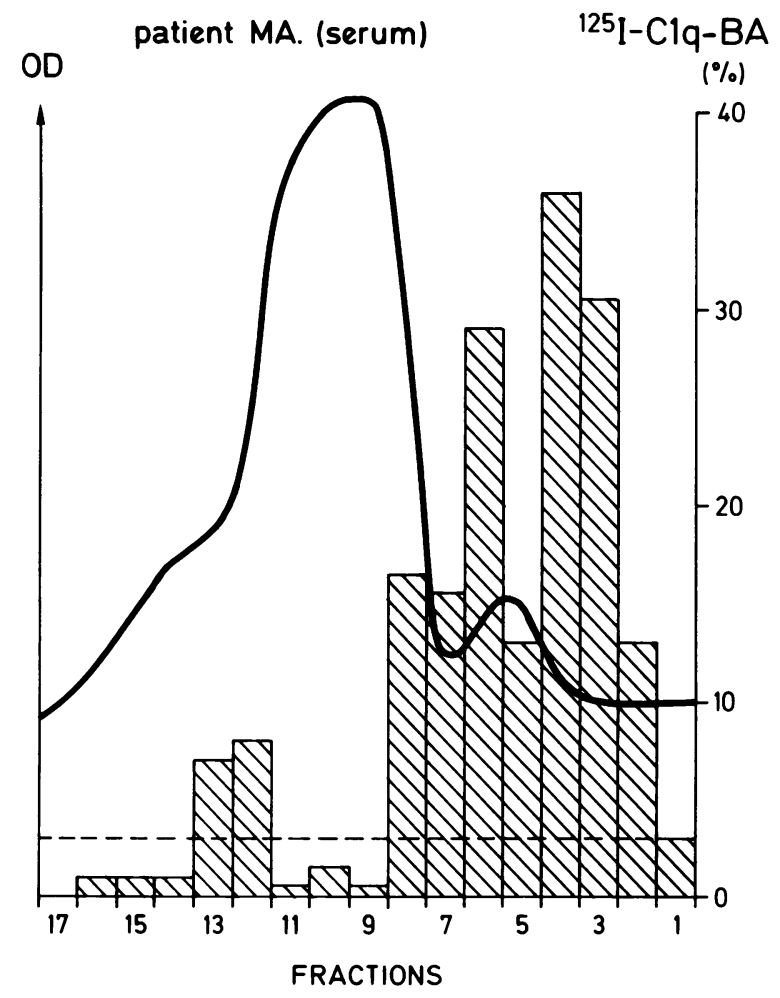

Figure $2 \quad 10-40 \%$ density gradient profiles of serum. The columns represent the ClqBA. - - -, Upper limit of ClqBA in fractions from a normal human serum simultaneously centrifuged. The tops of the tubes are on the left.

a significant negative correlation between $\mathrm{C} 3$ values and $\mathrm{ClqBA}(r=-0.56, P<0.005)$ or $\mathrm{KgBA}(\mathrm{R}=-0.42$, $P<0.025)$. The decrease of serum C3 does not appear to be related to a severe impairment of protein synthesis since serum albumin levels were within the normal range (mean $43.2 \pm 9.5 \mathrm{mg} / \mathrm{ml}$ ).

Circulating immune complexes in relation to polyclonal B cell activation, rheumatoid factor, and anti-

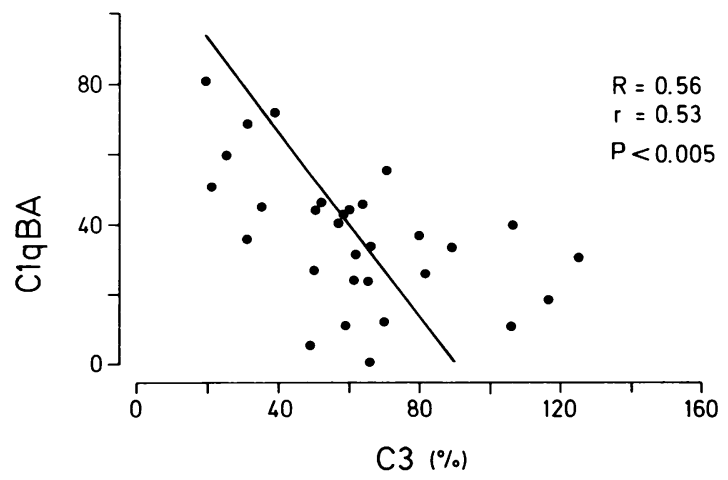

Figure 3 Correlation between ClqBA (percent precipitated) and C3 level (percentage of normal pool) in patients with African trypanosomiasis. trypanosome antibodies. African trypanosomiasis is known to be associated with a marked increase of immunoglobulin synthesis, with a polyclonal pattern (2). In 34 patients studied, high IgG and IgM serum levels $(34.8 \pm 13.6$ and $12.5 \pm 7.2 \mathrm{mg} / \mathrm{ml}$, respectively) were observed without any significant difference according to the stage of the disease. Circulating immune complexes were closely associated with the occurrence of polyclonal antibody synthesis. A very significant correlation was found between ClqBA $(\mathrm{R}=0.79, P<0.001)$ or $\mathrm{KgBA}(\mathrm{R}=0.69, P<0.001)$ and serum IgM levels (Fig. 4a) and to a lesser degree between $\mathrm{ClqBA}$ and serum IgG levels ( $\mathrm{R}$ $=0.55, P<0.001)$. There was no correlation between $\mathrm{KgBA}$ values and IgG levels $(\mathrm{R}=0.32$, NS). One feature of this polyclonal antibody synthesis is the occurrence of RF-like antiimmunoglobulin antibodies. Using a solid-phase radioimmunoassay for IgM-RF, high levels of RF were obtained in 23/31 sera. There was a significant correlation between $\mathrm{ClqBA}$ ( $\mathrm{R}$ $=0.69, P<0.001)$ or $\mathrm{KgBA}$ values $(\mathrm{R}=0.61, P<0.001)$ and RF levels (Fig. 4b).

Anti-trypanosome antibodies were detected in all patients' sera. There was no correlation between the titers of IgG or IgM anti-trypanosome antibodies and the IgG and IgM serum levels, nor with the levels of circulating IC (ClqBA and $\mathrm{KgBA}$ ) (Table I).

Immune complexes in cerebrospinal fluid during African trypanosomiasis. Immune complexes were detected by the ClqBA in 31 of 35 cerebrospinal fluid samples in patients with trypanosomiasis ( $P$ $<0.001$ ) (Fig. 5). There was no detectable Clq binding material in the five "normal" CSF samples. Similarly, in nine CSF samples from hospitalized African patients with other parasitic diseases, there was no increase in $\mathrm{ClqBA}$ although the $\mathrm{ClqBA}$ was slightly elevated (5-14\% precipitated) in the corresponding serum samples.

The $\mathrm{KgBA}$ was also performed on 32 of the $\mathrm{CSF}$ samples from patients with trypanosomiasis and elevated values were obtained in $45 \%(P<0.001)$. In both $\mathrm{ClqBA}$ and $\mathrm{KgBA}$ a marked elevation of the
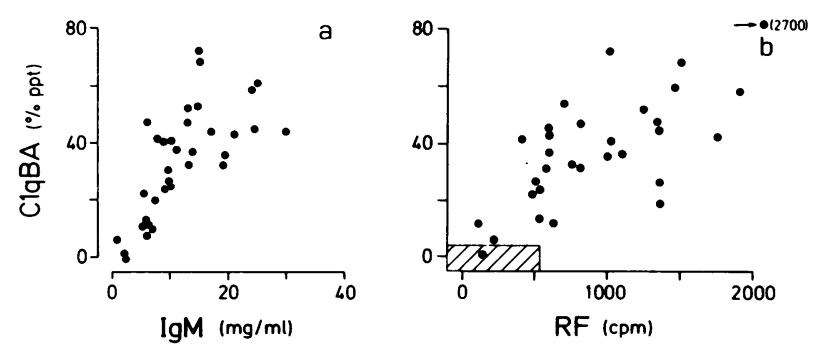

Figure 4 Correlation between the levels of immune complexes and of those of serum IgM (a) and of RF-like anti-IgG antibodies (b) from patients with trypanosomiasis. $\%$ ppt, percent precipitable. 
TABLE I

Anti-trypanosome Antibodies and Immune Complexes

\begin{tabular}{|c|c|c|c|c|c|c|c|}
\hline \multirow[b]{2}{*}{ Stage } & \multirow[b]{2}{*}{ Patient } & \multicolumn{2}{|c|}{$\begin{array}{l}\text { Anti-trypano- } \\
\text { some antibodies }\end{array}$} & \multirow{2}{*}{$\begin{array}{c}\text { Serum } \\
\text { IgG }\end{array}$} & \multirow{2}{*}{$\begin{array}{c}\text { Serum } \\
\text { IgM }\end{array}$} & \multirow[b]{2}{*}{$\mathrm{ClqBA}$} & \multirow[b]{2}{*}{ KgBA } \\
\hline & & $\mathrm{IgG}^{*}$ & $\mathrm{IgM}^{*}$ & & & & \\
\hline & & & & & & $\begin{array}{c}\% \mathrm{Clq} \\
\text { precipitated }\end{array}$ & 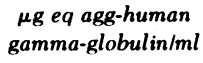 \\
\hline \multirow[t]{5}{*}{ I } & Eta. & 16 & 4 & 37 & 13 & 47 & 140 \\
\hline & Mib. & 40 & 320 & 56 & 14 & 37 & 42 \\
\hline & Mor. & 40 & 320 & 44 & 31 & 61 & 150 \\
\hline & Nzu. & 160 & 40 & 55 & 9 & 42 & 50 \\
\hline & Liz. & 1,220 & 80 & 40 & 7 & 13 & 16 \\
\hline \multirow[t]{4}{*}{ II } & Gra. & 40 & 640 & 42 & 13 & 39 & 44 \\
\hline & Mab. & 40 & 320 & 19 & 5 & 24 & 13 \\
\hline & Mor. & 160 & 320 & 23 & 7 & 20 & 90 \\
\hline & Nsi. & 80 & 320 & 33 & 16 & 68 & 65 \\
\hline \multirow[t]{5}{*}{ III } & Abo. & 20 & 80 & 42 & 14 & 52 & 180 \\
\hline & Tia. & 20 & 80 & 39 & 18 & 34 & 70 \\
\hline & Mpa. & 40 & 160 & 48 & 20 & 36 & 170 \\
\hline & Oke. & 160 & 160 & 24 & 10 & 27 & 72 \\
\hline & Ngo. & 320 & 160 & 38 & 18 & 59 & 117 \\
\hline
\end{tabular}

* Reciprocal value of the last positive dilution, by indirect immunofluorescence using anti-IgG or anti-IgM conjugate.

CSF values was seen in patients with a definite involvement of the central nervous system (stage III) as compared with earlier stages (I and II) of sleeping sickness (ClqBA, $P<0.005$; KgBA, $P<0.05$ ) (Fig. 5). The same CSF samples were analyzed for the protein content, the levels of IgG, IgM, albumin and C3, and for the serum protein pattern by immunoelectrophoresis. CSF samples with detectable trypanosomes

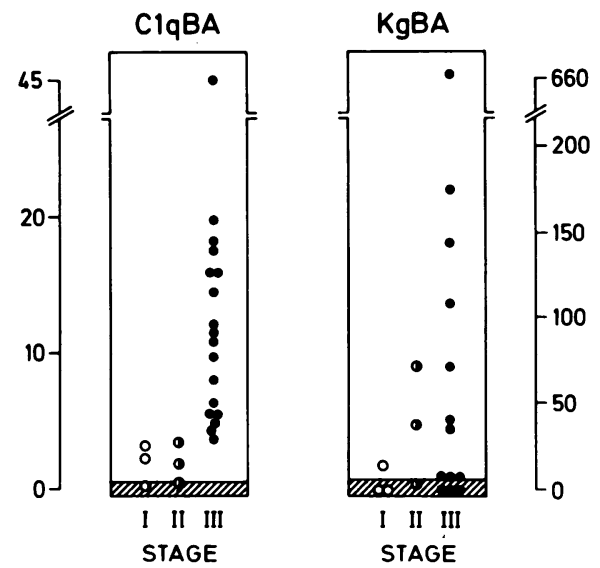

Figure 5 Immune complexes were detected by the ClqBA (percent precipitable) and $\mathrm{KgBA}$ (micrograms equivalent human gamma-globulin per milliliter) in cerebrospinal fluid from patients with African trypanosomiasis. Comparison between patients at stage I or II (no cerebral manifestations) with those at stage III (meningo-encephalitis). (stage II or III) contained more proteins than normal CSF. There was a modest increase in the albumin concentration but IgG $(1-49$, median $=16 \mathrm{mg} / \mathrm{dl})$ and IgM $(0-25$, median $=8 \mathrm{mg} / \mathrm{dl})$ levels were strikingly elevated. In two of three CSF samples analyzed after sucrose density ultracentrifugation, a peak of heavy IgG (>20S) was identified (Fig. 6). Small amounts of C3 $(0-1.4 \mathrm{mg} / \mathrm{dl})$ were also detected in CSF, particularly at stage III of the disease ( $8 / 10$ samples), whereas C3 was undetectable in control CSF samples. There was a significant correlation between CSF-IgG and CSF-albumin levels $(r=0.80, P<0.001)$ but not between CSF-IgM and CSF-albumin levels $(r=0.11$,

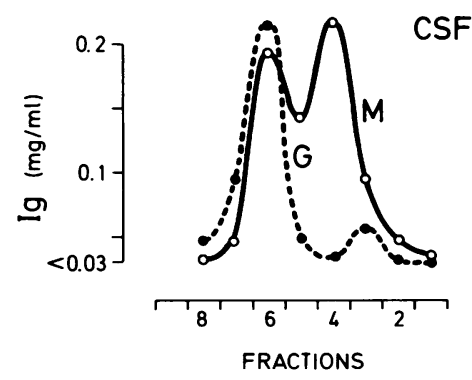

Figure 6 Sucrose density gradient fractionation of spinal fluid of one patient with African trypanosomiasis. The IgG and IgM concentrations in each fraction are indicated by interrupted and continuous lines, respectively. Fraction 8 corresponds to the top of the tubes. 
NS). The correlation between Clq-BA and IgG levels was significant $(r=0.50, P<0.01)$.

IgM and/or IgG anti-trypanosome antibodies were detected in 13/15 CSF samples tested (titers 1/4-1/64).

The origin of CSF immunoglobulins and CSF immune complexes. Comparison between the serum levels and the CSF levels of several serum proteins allows an evaluation of the relative integrity of the blood-brain barrier as well as the demonstration of a local synthesis of IgG and/or IgM in the CSF compartment (11). The concentration ratios $\mathrm{CSF} / \mathrm{serum}$ for albumin (Qalb) has been selected as a marker for the overall permeability of all structures that separate the serum from CSF (12). In most patients

TABLE II

Blood-Brain Barrier Function and Intracerebral IgG Synthesis in African Trypanosomiasis

\begin{tabular}{|c|c|c|c|c|c|c|c|}
\hline Patients & Stage & Qalb $\times 10^{-3 *}$ & $\begin{array}{c}\text { Impairment of } \\
\text { CSF/blood } \\
\text { barriert }\end{array}$ & QIgG $\times 10^{-3 *}$ & $Q \operatorname{IgM} \times 10^{-3 *}$ & IgG index $\S$ & $\begin{array}{l}\text { IgG synthesized } \\
\text { in CNS }\end{array}$ \\
\hline & & & & & & & $\mathrm{mg} / 100 \mathrm{ml} \mathrm{CSF}$ \\
\hline Kiv. & I & 3.00 & None & 0.29 & 0.1 & 0.1 & -2.89 \\
\hline Eta. & I & 3.27 & None & 0.27 & 0.1 & 0.08 & -7.20 \\
\hline Ngu. & I & 4.07 & None & 2.08 & 0.1 & 0.51 & -6.34 \\
\hline Nsi. & II & 3.62 & None & 1.22 & 32.05 & 0.34 & -3.91 \\
\hline Mak. & II & 9.51 & Slight & 5.51 & 1.38 & 0.58 & +1.36 \\
\hline Mab. & II & 12.89 & Slight & 18.75 & 83.93 & 1.45 & +28.11 \\
\hline Tia. & III & 4.47 & None & 10.00 & 0.55 & 2.23 & +27.49 \\
\hline Bus. & III & 5.48 & None & 10.66 & 68.18 & 1.94 & +11.22 \\
\hline Bak. & III & 5.65 & None & 6.17 & 2.60 & 1.09 & +9.43 \\
\hline Luz. & III & 6.86 & None & 5.68 & 20.69 & 0.83 & +3.33 \\
\hline Mpa. & III & 7.18 & None & 5.79 & 5.26 & 0.80 & +8.55 \\
\hline Bul. & III & 8.40 & Slight & 7.89 & 209.09 & 0.94 & +5.21 \\
\hline Ngo. & III & 9.53 & Slight & 3.12 & 50.67 & 0.33 & -6.36 \\
\hline Oke. & III & 9.60 & Slight & 0.40 & 14.00 & 0.04 & -10.28 \\
\hline Ndu. & III & 10.57 & Slight & 9.37 & 0.33 & 0.88 & +13.09 \\
\hline Min. & III & 55.94 & Severe & 60.45 & 593.33 & 1.08 & +50.28 \\
\hline \multicolumn{8}{|c|}{$\begin{array}{l}\text { Other hos- } \\
\text { pitalized } \\
\text { African } \\
\text { patients }\end{array}$} \\
\hline Bos. & & 3.9 & None & 1.5 & $<0.1$ & 0.38 & -1.13 \\
\hline Mua. & & 7.0 & None & 3.7 & $<0.1$ & 0.53 & -4.36 \\
\hline Mag. & & 3.7 & None & 1.6 & $<0.1$ & 0.43 & -1.15 \\
\hline Ndi. & & 2.8 & None & 1.4 & $<0.1$ & 0.50 & -1.08 \\
\hline Mor. & & 2.7 & None & 1.1 & $<0.1$ & 0.41 & -2.22 \\
\hline Kon. & & 2.5 & None & 1.3 & $<0.1$ & 0.52 & -1.47 \\
\hline Kia. & & 2.2 & None & 1.5 & $<0.1$ & 0.68 & -0.45 \\
\hline Oye. & & 3.2 & None & 4.2 & $<0.1$ & 1.31 & +1.97 \\
\hline Was. & & 2.9 & None & 2.0 & $<0.1$ & 0.69 & -0.11 \\
\hline Normal & & $3.7-7.2$ & None & $1.7-2.6$ & $\sim 0.1$ & $0.47-0.58$ & $-1.98-0.66$ \\
\hline
\end{tabular}

Alb, albumin.

* Qalb, CSFalb/Salb; QIgG, CSFIgG/SIgG; QIgM, CSFIgM/SIgM.

‡ According to (13), no impairment, Qalb $=7.2 \times 10^{-3}$; slight impairment, Qalb = $7.7-14 \times 10^{-3}$; moderate impairment, Qalb $=14-33 \times 10^{-3}$; severe impairment, Qalb $=33-100 \times 10^{3}$. Normal values vary from $3.6 \pm 1.7 \times 10^{-3}$ (at $17-30 \mathrm{yr}$ ) to $4.6 \pm 1.3 \times 10^{-3}$ (at $41-50 \mathrm{yr}$ ).

\$IgG index, QIgG/Qalb.

"Concentration of CSF-IgG synthesized within the CNS. Calculated according to Tourtellotte's formula:

IgG $_{\mathrm{CSF}}-\left(\frac{\text { IgG serum }}{369}\right)-\left[\left(\right.\right.$ albumin $\left.\left._{\mathrm{CSF}}-\frac{\text { albumin serum }}{230}\right)\left(\frac{\text { IgG serum }}{\text { albumin serum }} \times 0.43\right)\right]$

= locally synthesized IgG/100 $\mathrm{ml}$ of CSF. 
with trypanosomiasis, no or only slight impairment of the CSF blood barrier state was observed (Table II).

In contrast to the relatively moderate changes in the blood/CSF permeability for albumin, high CSF/ serum ratios were observed for IgG (QIgG) and/or IgM (QIgM) in all patients at stage II and III (Table II). Low molecular weight (7S) IgM was investigated by immunochemical analysis of sucrose density gradient fractions in three CSF samples with a high IgM content. In all three, there was a spreading of IgM in 7 to $19 S$ fractions; in one of them, two IgM peaks were identified in 7 and $19 \mathrm{~S}$ positions, whereas the corresponding serum samples did not contain $7 \mathrm{~S}$ IgM. These results were consistent with an intracerebral synthesis of IgG and IgM, which was further suggested by the analysis of the QIgG/Qalb ratios, or "IgG index" according to Tibbling et al. (11) (Fig. 7). Indeed, this ratio, which does not vary with age in normal individuals (11), was markedly increased in 10/13 patients at stage II or III (Table II). In the remaining two patients, a high CSF/serum IgM ratio was observed. The concentration of locally synthesized IgG in CSF was calculated using Tourtellotte's formula (13). These values were in the normal range in the CSF samples collected at stage I, but were elevated in 10/13 CSF samples collected from patients at stage II or III. The $3 / 13$ negative samples displayed an elevation of IgM and QIgM suggestive of a local IgM synthesis. Correlations between, on one hand, the levels of circulating IC, detected by the ClqBA and the $\mathrm{KgBA}$ and, on the other hand, the levels of IC in CSF, were not significant (Fig. 8). Several CSF samples were more positive than the corresponding serum samples (Fig. 8). The correlation between the level of IC in CSF and the Qalb ratio

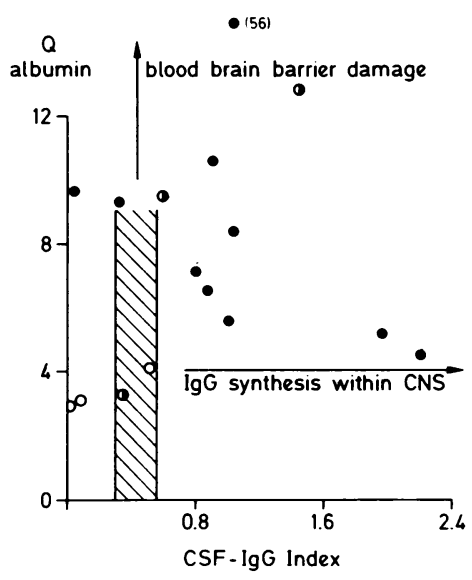

FIGURE 7 Graphical representation of the evaluation of blood-brain barrier function by $\mathrm{CSF} /$ serum albumin ratio (Qalb) and of IgG synthesis in CNS by CSF-IgG index (QIgG/Qalb). The hatched area shows the normal limits (11). For symbols, see legend to Fig. 4.
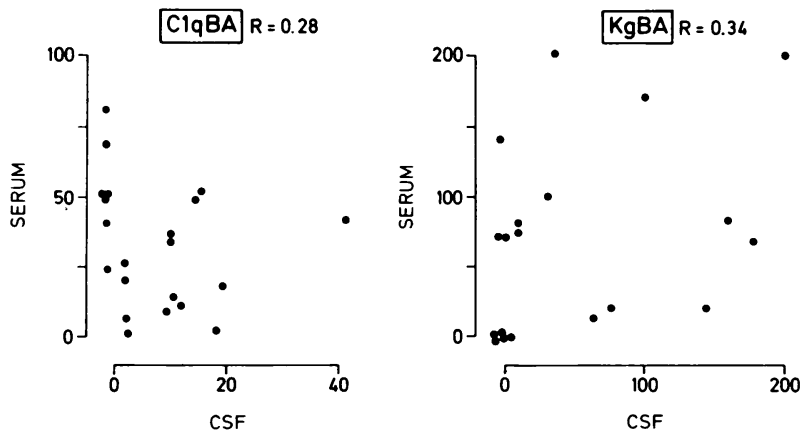

Figure 8 Correlation analysis between the levels of immune complexes in serum and in corresponding CSF samples. $\mathrm{ClqBA}$ values are expressed in percent Clq precipitated; $\mathrm{KgBA}$ values in micrograms equivalent human gamma globulin per milliliter.

was not significant but there was a correlation of CSF-ClqBA with the IgG index $(r=0.50, P<0.025)$. In the nine CSF samples from other African hospitalized patients studied, the IgG level was low (median $2.6 \mathrm{mg} / \mathrm{dl}$ ) and there was no detectable IgM. There was no indication of an increased intracerebral IgG synthesis.

Evolution of circulating IC and CSF-IC during therapy. Eight patients were followed during the trypanocidal therapy. In three patients, there was a marked decrease of serum IgM (25 to $10 ; 20$ to 0.3 ; 22 to $13 \mathrm{mg} / \mathrm{ml}$ ) and of ClqBA (47 to $14 ; 40$ to 2 ; 38 to $10 \%$ ) during the first $3 \mathrm{wk}$, but only small changes were seen in the others. A significant decrease of the serum IgG level was seen in only one of these eight patients. In one patient with encephalitis, who had already suffered from three relapses of trypanosomiasis during the previous $2 \mathrm{yr}$, several samples of CSF and serum were collected serially. Although the ClqBA and $\mathrm{KgBA}$ decreased to normal values after $30 \mathrm{~d}, \mathrm{ClqBA}$ remained elevated in CSF 18 mo after this course of treatment.

\section{DISCUSSION}

This study demonstrates the presence of circulating immune complexes in patients infected with trypanosomes. It confirms experimental data obtained in mice $(5,15)$ and preliminary human studies (16). The IClike material that appears in most patients from the early stage of infection, can be detected using two different techniques with a significant correlation between the two sets of results. These two techniques, which were based on the reactivity of IC with $\mathrm{Clq}$ or of C3-coated IC with conglutinin, had previously been shown to detect a wide range of IC sizes (8). These data suggest that this material represents in vivo formed IC and this hypothesis is further supported by the significant negative correlation between $\mathrm{ClqBA}$ 
and levels of $\mathrm{C} 3$ in serum. The persistence of circulating IC during the entire course of the disease, even at stages when there is a very low parasitemia, suggests that parasitic antigens do not represent a main component of the IC. Besides, high levels of serum immunoglobulins were found in the patients studied. Recently, we demonstrated a variety of antibodies against haptens, hemocyanin, ovalbumin, DNA, and sheep erythrocytes in serum from these patients, suggesting an extensive expression of the $B$ cell repertoire including the occurrence of anti-IgG antibodies similar to rheumatoid factor (manuscript in preparation). The highly significant correlation between the ClqBA and the level of RF would be consistent with an involvement of $R F$ in the generation of circulating IC in this disease. This would be similar to the situation observed in mice undergoing a polyclonal antibody synthesis after injection of bacterial lipopolysaccharide. Indeed, it was found recently that in mice injected with bacterial lipopolysaccharide, there is an induction of circulating IC closely correlated with the occurrence of anti-immunoglobulin antibodies. ${ }^{2}$ Therefore, it is possible that IC appearing in trypanosomiasis are part of the expression of a polyclonal B cell activation.

A localization of IC in the CNS has been suggested by the demonstration of electron-dense deposits in the basement membrane of choroid plexus in patients with systemic lupus erythematosus and in NZBxNZW mice (17). In addition, deposits of IgG, bovine serum albumin, and C3 were shown in the choroid plexus of rabbits undergoing an acute IC disease (18). The latter model was associated with a slight alteration in the blood CSF barrier permeability, but IC were usually not detectable in the CSF. In experimental trypanosomiasis, a progressive involvement of the CNS was found parallel to a progressive appearance of electrondense deposits in the endothelial and in the subependymal layers of the choroid plexus basement membrane (15). Our data demonstrate the presence of IC in CSF during the encephalitis stage of trypanosomiasis in man. We do not think that the occurrence of IC in CSF primarily results from a diffusion from serum to CSF through the blood brain barrier. First, IC are detectable in serum in large amounts in the few patients studied at the early stage of infection, without a concomitant appearance of IC in CSF. Secondly, at later stages, there is no correlation between the level of circulating IC and that of CSF-IC. In fact, most patients appear to have a normal or only slightly altered blood-brain barrier, which is probably efficient in preventing an appreciable crossing of IC from serum to CSF.

\footnotetext{
${ }^{2}$ Ramos Niembro, F., and P. H. Lambert. The triggering of circulating immune complexes by polyclonal $B$ cell activators in mice. Submitted for publication.
}

However, one cannot entirely exclude the possibility that an active equilibrium may be involved in the observed picture of a blood-brain barrier for IC.

The appearance of IC in CSF at the encephalitic stage of African trypanosomiasis was closely associated with increased IgG and/or IgM levels in CSF. There was a dissociation between a moderate increase of the CSF/serum albumin ratio and high values of the CSF/serum IgG or IgM ratios. This leads to high values of "IgG index" which indicate that the majority of these immunoglobulins is synthesized within the CNS compartment (11). The quantitation of locally synthesized IgG in CSF was carried out using Tourtellotte's formula (13), which can be used when the blood-brain barrier is not too altered (CSF/serum albumin ratios lower than 10 $\left.\times 10^{-3}\right)(19)$. This is the case in $14 / 16$ of our patients (Table I). The elevation of intracerebral IgG synthesis is comparable with that observed in patients with subacute sclerosing panencephalitis and many reflect a similar reaction to the infectious process (19). This increased IgG synthesis, which is concomitant with the occurrence of trypanosomes in CSF, may reflect an immune response to trypanosome antigens, as suggested by the relatively high levels of antitrypanosome antibodies in CSF, or to some autoantigens. It may also depend on an oligoclonal or polyclonal B cell activation in the CNS compartment.

Therefore, IC appearing in CSF are probably formed locally and may involve trypanosome antigens or autoantigens such as IgG or CNS antigens. A local formation of IC would be consistent with the observed correlation between the level of Clq-BA and the level of the IgG index. One should note that IC have also been demonstrated in CSF in patients with subacute sclerosing panencephalitis or multiple sclerosis (20).

The detection of IC in CSF during trypanosomiasis appears as a potentially useful marker for the early diagnosis of cerebral involvement in this disease and for the persistence of CNS infection during therapy. The significance of these results should also be considered in relation to the evaluation of the CNS involvement in systemic lupus erythematosus and other IC diseases.

\section{ACKNOWLEDGMENTS}

The authors express their gratitude to Mrs. Martine Devouge and Mrs. Jean Ringrose for their secretarial help. We thank Mr. G. Rapin for preparing the graphical material and Mr. M. Barnet for his technical assistance.

\section{REFERENCES}

1. Baker, J. R. 1974. Epidemiology of African Sleeping Sickness. In Trypanosomiasis and Leishmaniasis. Ciba Found. Symp. 20: 29-43. 
2. Greenwood, B. M. 1974. Possible role of a B-cell mitogen in hypergammaglobulinaemia in malaria and trypanosomiasis. Lancet. I: 435-437.

3. Louis, J. A., and P. H. Lambert. 1979. Lipopolysaccharides: from immunostimulation to autoimmunity. Springer Semin. Immunopathol. 2: 215-228.

4. Greenwood, B. M., and H. C. Whittle. 1973. Cerebrospinal fluid IgM in patients with sleeping sickness. Lancet. II: 525-527.

5. Galvao Castro, B., A. Hochmann, and P. H. Lambert. 1978. The role of the host immune response in the development of tissue lesions associated with African trypanosomiasis in mice. Clin. Exp. Immunol. 33: 12-24.

6. Zubler, R. H., G. Lange, P. H. Lambert, and P. A. Miescher. 1976. Detection of immune complexes in unheated serum by a modified ${ }^{125} \mathrm{I}-\mathrm{Clq}$ binding test. Effect of heating on the binding of $\mathrm{Clq}$ by immune complexes and application of the test to systemic lupus erythematosus. J. Immunol. 116: 232-235.

7. Casali, P., A. Bossus, N. A. Carpentier, and P. H. Lambert. 1977. Solid-phase enzyme immunoassay or radioimmunoassay for the detection of immune complexes based on their recognition by conglutinin: conglutinin binding test. Clin. Exp. Immunol. 29: 342-354.

8. Casali, P., P. Duprez, A. Bossus, and P. H. Lambert. 1978. Solid-phase assay for the detection of immune complexes based on their recognition by conglutinin: conglutinin binding test. Quantitation of the conglutininbound complex by ${ }^{125}$ I-labelled protein A. In Manual of Techniques in Immunology and Virology for Cancer Research Workers. J. P. Lamelin and G. Lenoir, editors. International Agency for Research and Cancer, Lyon. III: $1.1-11$.

9. Lanham, S. M., and D. G. Godfrey. 1970. Isolation of salivarian trypanosomes from man and other mammals using DEAE-cellulose. Experimental Parasitol. 28: 521534.

10. Lowry, O. H., N. Y. Rosenbrough, A. C. Farr, and R. J. Randall. 1951. Protein measurement with the Folin phenol reagent. J. Biol. Chem. 193: 265-275.

11. Tibbling, G., H. Link, and S. Ohman. 1977. Principles of albumin and IgG analysis in neurological disorders.
I. Establishment of reference values. Scand. J. Clin. Lab. Invest. 37: 385-390.

12. Schliep, G., and K. Felgenhauer. 1978. Serum-CSF protein gradients, the blood-CSF barrier and the local immune response. J. Neurol. 218: 77-79.

13. Tourtellotte, W. W. 1970. On cerebrospinal fluid IgG quotients in multiple sclerosis and other diseases. A review and a new formula to estimate the amount of IgG synthesized per day by the central nervous system. $J$. Neurol. Sci. 10: 279-286.

14. Hay, F. C., L. J. Nineham, G. Torrigiani, and I. M. Roitt. 1976. "Hidden" IgG antiglobulins in normal human serum. Clin. Exp. Immunol. 25: 185-190.

15. Poltera, A. A., A. Hochmann, W. Rudin, and P. H. Lambert. 1980. Trypanosoma brucei brucei: a model for cerebral trypanosomiasis in mice-an immunological, histological and electron microscopic study. Clin. Exp. Immunol. 40: 496-507.

16. Fruit, J., F. Santoro, D. Afchain, G. Duvallet, and A. Capron. 1977. Les immuns-complexes circulants dans la trypanosomiase africaine humain et expérimentale. Ann. Soc. Belg. Méd. Trop. 57: 257-263.

17. Lampert, P. W., and M. B. A. Oldstone. 1973. Host immunoglobulin $G$ and complement deposits in the choroid plexus during spontaneous immune complex disease. Science (Wash. D. C.). 180: 408-410.

18. Harbeck, R. J., A. A. Hoffman, S. A. Hoffman, and D. W Shucard. 1979. Cerebrospinal fluid and the choroid plexus during acute immune complex disease. Clin. Immunol. Immunopathol. 13: 413-425.

19. Ewan, P. W., and P. J. Lachmann. 1979. IgG synthesis within the brain in multiple sclerosis and subacute sclerosing panencephalitis. Clin. Exp. Immunol. 35: 227235.

20. Oldstone, M. B. A. 1979. Virus persistence and escape from immune surveillance. In The Menarini Series on Immunopathology. (Proceedings of Symposium on Immunopathology of the Central and Peripheral Nervous System.) P. A. Miescher, L. Bolis, S. Gorini, T. A. Lambo, G. J. V. Nossal, and G. Torrigiani, editors. Schwabe \& Co., Basle. 2: 123-134. 